\title{
Heart rate variability parameters are decreased in obese adults
}

\section{Alma Agačević*, Larisa Ščetić Mešan, Alma Sijamija, Nedžad Hadžić}

Public Health Institution Hospital Travnik, Travnik, Bosna and Herzegovina
KEYWORDS: heart rate variability, body mass index, obesity.

CITATION: Cardiol Croat. 2016;11(10-11):411-412. | DoI: http://dx.doi.org/10.15836/ccar2016.411

*ADDRESS FOR CORRESPONDENCE: Javna ustanova Bolnica Travnik, Kalibunar bb, 72270 Travnik Bosna i Hercegovina. / Phone: +387-61-328684 / E-mail: agacevic.alma@gmail.com

ORCID: Alma Agačević, http://orcid.org/0000-0003-4671-0991 • Larisa Ščetić Mešan, http://orcid.org/0000-0003-1709-7366 Alma Sijamija, http://orcid.org/0000-0003-2818-0501 • Nedžad Hadžić, http://orcid.org/0000-0002-0261-3754

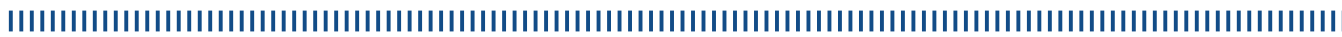

Objectives: To evaluate an association between body mass index (BMI) and the cardiac autonomic activity by measuring heart rate variability (HRV), in obese and non-obese adults.

Patients and Methods: Cross-sectional data of 116 participants (54.3\% females, age: $54.27 \pm 15.58$ years, BMI: $28.25 \pm 5.53 \mathrm{~kg} / \mathrm{m}^{2}$ ) were included in analysis. HRV data were analyzed in time and frequency domains using customized program CARDICODE 300 (type:HT312), obtained from 24 hours, day and night-time segments of Holter monitoring. Analysed HRV indices were: total power (TP), low-frequency power (LF), high-frequency power (HF), square root of the mean squared differences of successive normal

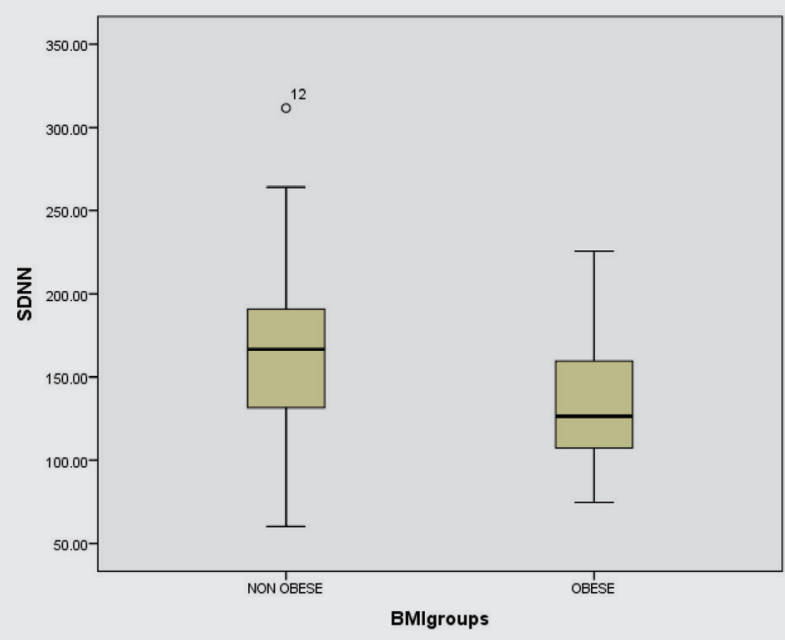

The solid horizontal line denotes the median value of SDNN obese and non obese patients, the box represents the $25^{\text {th }}$ and $75^{\text {th }}$ interquartile range. The whisker represents the minimum and maximum value. The median value of SDNN in the non obese group was $163.0163 \mathrm{~ms}$. Range of minimal and maximal values in this group was $60.10-311.60 \mathrm{~ms}$. The median value of SDNN in obese group was $135.6833 \mathrm{~ms}$ Range of minimal and maximal values in this group was $74.50-225.80 \mathrm{~ms}$, which is statistically significant lower $(\mathrm{p}<0.05)$

FIGURE 1. The values of SDNN (standard deviation of normal to normal RR interval) in obese and non-obese group.

RECEIVED:

September 25, 2016

ACCEPTED:

October 10, 2016

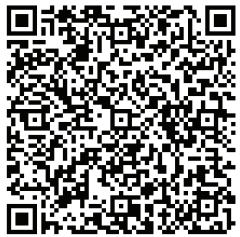

to normal intervals (rMSSD), standard deviation of normal to normal RR interval (SDNN) and the proportion derived by dividing number of interval differences of successive NN intervals greater than $50 \mathrm{~ms}$ by the total number of NN intervals (pNN50). BMI was obtained according to common calculation using anthropometric measurements (weight, height) (kg/m²). Participants were grouped according to BMI into non obese (BMI $30 \mathrm{~kg} / \mathrm{m}^{2}, \mathrm{n}=80$ ) and obese (BMI $\geq 30 \mathrm{~kg} / \mathrm{m}^{2}, \mathrm{n}=36$ ).

Results: Mean values of all analyzed HRV parameters (SDNN, rMSSD, PNN50, TP, LF and HF) were lower in obese compered to non-obese participants (Figures 1, 2, and 3). Statistically significant differences was found for SDNN, TP ( $p=0.002$, p=0.01 respectively, using parametric independent samples t-test), and for pNN50 ( $\mathrm{p}=0.036$, using nonparametric Mann-Whitney U test). Conclusion: These results support previous findings ${ }^{1,2}$ that HRV parameters are decreased in obese adults suggesting reduced both sympathetic and vagal autonomic regulation of heart. 


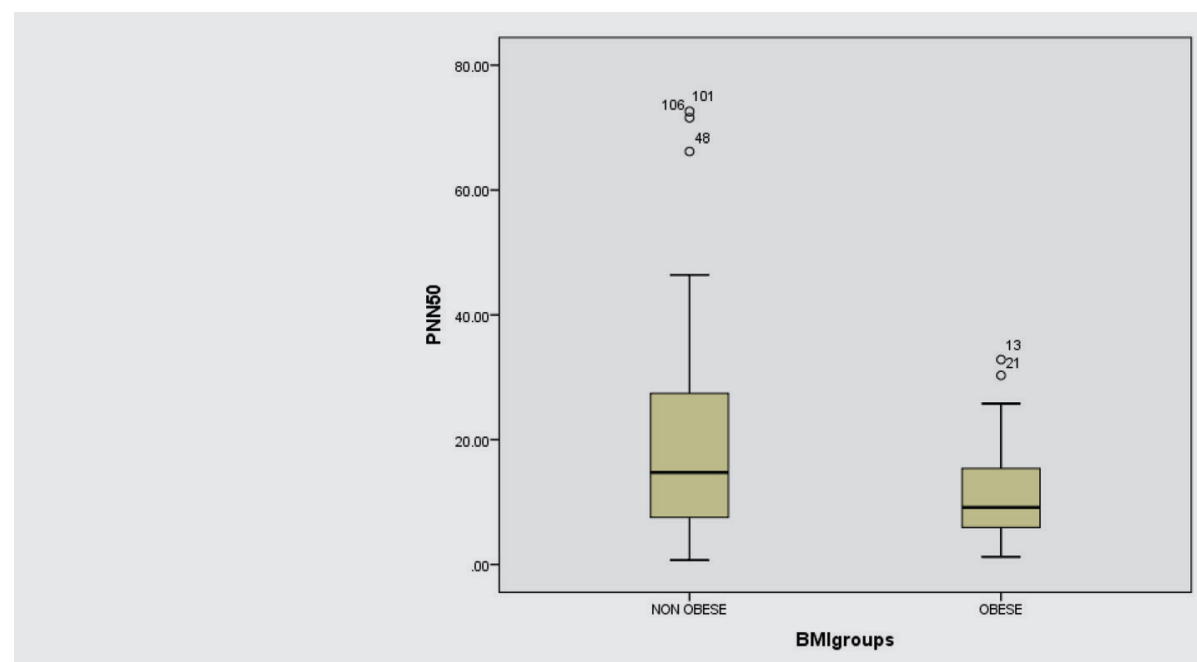

The solid horizontal line denotes the median value of PNN50 obese and non obese patients, the box represents the $25^{\text {th }}$ and $75^{\text {th }}$ interquartile range. The whisker represents the minimum and maximum value. The median value of PNN50 in the non obese group was $18.7600 \%$. Range of minimal and maximal values in this group was $0.70-72.60 \%$. The median value of PNN50 in obese group was $11.6972 \%$.

Range of minimal and maximal values in group was $1.20-32.80 \%$, which is statistically significant lower $(\mathrm{p}<0.05)$

FIGURE 2. The values of PNN50 (the proportion derived by dividing number of interval differences of successive NN intervals greater than $\mathbf{5 0}$ ms by the total number of NN intervals) in obese and non-obese group.

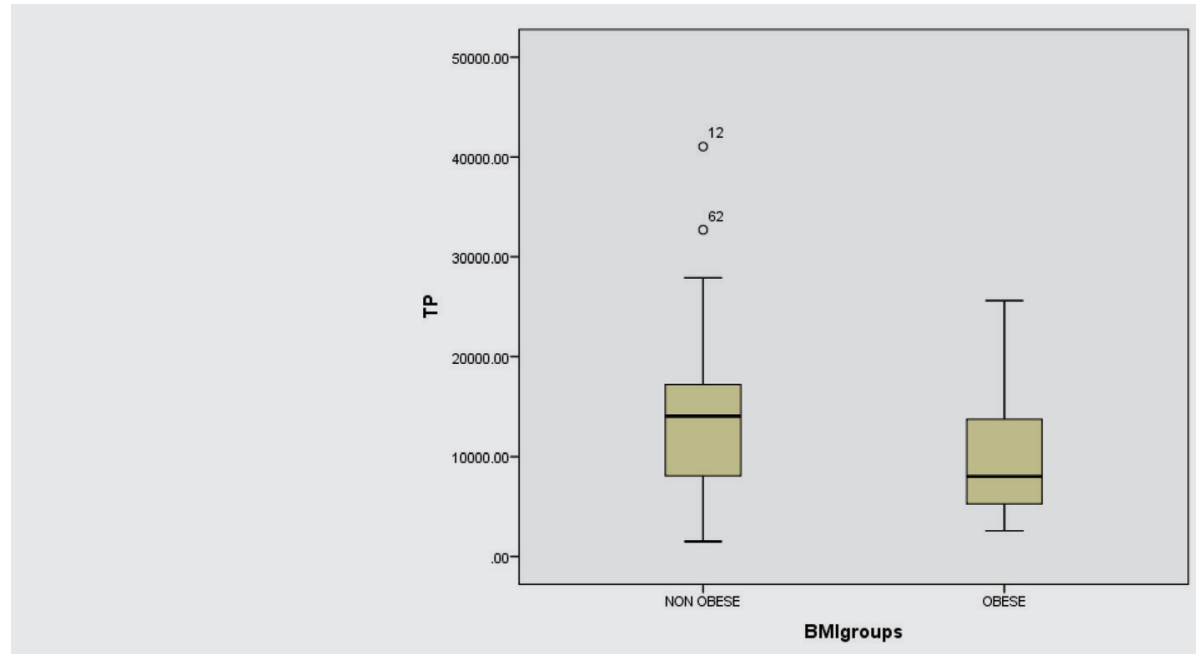

The solid horizontal line denotes the median value of TP obese and non obese patients, the box represents the $25^{\text {th }}$ and $75^{\text {th }}$ interquartile range. The whisker represents the minimum and maximum value. The median value of TP in the non obese group was $13539.3000 \mathrm{~ms} * \mathrm{~ms}$. Range of minimal and maximal values in this group was $1481.10-41059.90 \mathrm{~ms} * \mathrm{~ms}$. The median value of TP in obese group was $10083.0500 \mathrm{~ms} * \mathrm{~ms}$. Range of minimal and maximal values in group was $2566.00-25625.60 \mathrm{~ms} * \mathrm{~ms}$, which is statistically significant lower $(p<0.05)$.

FIGURE 3. The values of total power (TP) in obese and non-obese group.

1. Koenig J, Jarczok MN, Warth M, Ellis RJ, Bach C, Hillecke TK, et al. Body mass index is related to autonomic nervous system activity as measured by heart rate variability--a replication using short term measurements. J Nutr Health Aging. 2014;18(3):300-2. DOI: http://dx.doi.org/10.1007/s12603-014-0022-6

2. Yi SH, Lee K, Shin DG, Kim JS, Kim HC. Differential association of adiposity measures with heart rate variability measures in Koreans. Yonsei Med J. 2013:54(1):55-61. DOI: http://dx.doi.org/10.3349/ymj.2013.54.1.55 